\title{
The Attitude, motivation influence people's buying Luxury goods: A survey of Chinese in China
}

\author{
JI YI; Meng Fang Yuan; Suresh Kumah \\ President University Bekasi-West Jawa Indonesia
}

\begin{abstract}
Despite recent global economic downturns around the world, but Luxury goods still the popularity as some of the most popular products in the world. Now-days, more and more people know about Luxury goods and interested with Luxury goods. China has become the largest Luxury goods purchaser market. From the report 2013 it shows that Chinese people have buy 25\% of the Luxury goods in the world(Husband, P,2010). Luxury goods to be researched in my report were only included expensive accessory which are watches, bags, shoes, apparel, perfumers and so on. This article discussion about the facts that the attitude, motivation influence Chinese people buying Luxury goods. However, there mainly are three luxury consumer groups in China: the rich flaunting fortune and manifesting identity, the young people gaining a sense of satisfaction and the bribers for mutual collusion and commercially "hidden rules."( Wood, Zoe,2011) With the rapid development of national economy and the enhancement of the purchasing power, the luxury consumption Chinese people also got a certain development. The consumer perception of the people to the luxury goods needs to be guided and showing off the wealth to prove their self-esteem shows a lack of intrinsic value.
\end{abstract}

Keywords: Luxury Goods, customer Psychology, buying behavior, buying motivation

\section{Introduction}

The purchasing power of Chinese consumers rises with each passing day.In recent years, Chinese consumers have become the largest consumer group of luxury brands in the world.(Husband, P,2010) According to a new report compiled by HSBC, about a quarter of the world's luxury purchases are now made by Chinese citizens.which means $25 \%$ of luxury goods. Go through te HSBC report it shows that in 2007, china only purchasing $5 \%$ of luxury goods in the world. It's increasing by $5 \%$ each years and the expert think the number of increasing will be more and more. The purchasing of Luxury goods was increasing by huge number and very fast speed. The increasing speed was similar with the China GDP growing.(Bouee,2012) This report will deeply researched on why Chinese buy a lots of goods.

Luxury goods to be researched in my report were only included expensive accessory which are watches, bags, shoes, apparel, perfumers and so on. How can a Chinese people buy a lots of Luxury goods? Chinese buying Luxury goods it shows the China economics has been increasing. Since 2000, the China economic GDP was increased a lot. China's gross domestic product stood at US\$3.38 trillion while Germany's GDP was USD \$3.32 trillion for 2007. This made China the world's third largest economy by gross domestic product.Based on these figures, in 2007 China recorded its fastest growth since 1994 when the GDP grew by 13.1 percent.(Xin,2009))The increasing economic was the most important reason to push Chinese buy Luxury goods. Because the Chinese become more and more reach. They try to have a better life and pursue the famous and precious brand. Before 2012 the American and Japan were the largest Luxury goods purchaser.(Bouee,2012)

Other reason was also irritate Chinese to buy Luxury goods very crazy. Luxury goods refer to those top branded consumer products which are beyond the living needs of ordinary people. Therefore, the foreign luxury lovers and collectors tend to be the old and rich people. The luxury goods mostly are products with cultural connotations and owning the luxury goods means to have a culture. However, there mainly are three luxury consumer groups in China: the rich flaunting fortune and manifesting identity, the young people gaining a sense of satisfaction and the bribers for mutual collusion and commercially "hidden rules."( Wood, Zoe,2011) With the rapid development of national economy and the enhancement of the purchasing power, the luxury consumption Chinese people also got a certain development. The consumer perception of the people to the luxury goods needs to be guided and showing off the wealth to prove their self-esteem shows a lack of intrinsic value. If the people of a state become materialistic and especially worship the luxury goods, it will mislead and distort people's value of the society, increase the psychological imbalance of low-income groups and affect the social harmony and stability.

The purpose of this research is to analysis what are the most important etc that makes Chinese purchasing Luxury goods? 


\subsection{Theories of definition}

\section{Litureture Review}

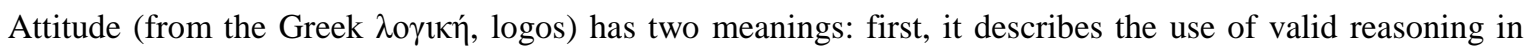
some activity; second, it names the normative study of reasoning or a branch thereof. In the latter sense, it features most prominently in the subjects of philosophy, mathematics, and computer science.

Motivation is a psychological feature that arouses an organism to act towards a desired goal and elicits, controls, and sustains certain goal-directed behaviors. It can be considered a driving force; a psychological one that compels or reinforces an action toward a desired goal. For example, hunger is a motivation that elicits a desire to eat. Motivation is the purpose or psychological cause of an action.

Influence is a power affecting a person, thing, or course of events, especially one that operates without any direct or apparent effort: relaxed under the influence of the music; the influence of television on modern life.

\subsection{Hypothesis \\ 2.21 relationships between tourism overseas and buying behaver}

First, we can not be questioned is our luxury consumer market presents a huge potential for development, and contains two key growth drivers, namely: Chinese mainland market demand for luxury goods, and the Chinese people to the increase in the number of overseas travel.Is there any effects because more and more Chinese starting travel overseas. Chinese Though Chinese nationals continue to account for a large proportion of luxury purchases, only about $10 \%$ of those sales are actually transacted in mainland China. The rest of the purchases are frequently made overseas in territories like Hong Kong and countries like Australia, where a booming influx of Chinese visitors routinely spend triple the amount compared to the average American tourist.

\section{H1: Tourism overseas has influence buying behaver}

\subsection{2 relationship between price advantage and buying behaver}

According to the theory of consumer surplus, consumer spending goods or services for the purpose of gain utility, so the time of purchase, consumers always want to pay the money obtained to compare the effectiveness, measure, so that the payment of money to receive maximum effectiveness. It can be seen, the consumer is actually based on their usefulness for goods or services purchased wished to determine the amount of money paid. However, the actual price of goods on the market are often not in line with his subjective desire, does not necessarily mean that he wished to pay the price, which there is a difference between the price that consumers wish to pay the difference between the actual price and the market. If consumers buy a certain product or service is lower than the actual price he is willing to pay the price, consumers will get a surplus. This is why the outbound travel of Chinese citizens in the thermal loyal biggest reason to buy luxury goods. Purchase price of luxury goods in the country than in the foreign higher than $1 / 3$ of the price. Three-quarters of respondents said that foreign luxury goods priced lower than the domestic consumption of the important reasons is the drive (priced lower than domestic; $74 \%$ of the original authentic; $56 \%$ higher than the domestic rich product selection; $48 \%$ good service; $31 \%$ There are promotions or promotional package; $31 \%$ comfortable shopping environment; $30 \%$ mall is conveniently located; $22 \%$ just passing through; 22\% promotional efforts; $9 \%$ with small packaging products; $8 \%$ large packaging products; $7 \%$ ); followed by is quality assurance, nearly $60 \%$ of consumers believe that the purchase of luxury goods abroad more comfortable, able to guarantee to buy the "real thing"; Meanwhile, almost half of the respondents visitors (48 percent) believe that foreign brand variety, compared to domestic and greater choice.

Conformity with the imitative consumption of consumer choice is not entirely the result of personal choice independently, often subject to the influence of others. One result of this effect is to produce herd consumption. Means an individual from outside the so-called herd behavior of the crowd, while the judge in his own perception, cognitive performance in line with the majority in public opinion or behavior. In general, the behavior of group members, often have a tendency to follow the group, when he found his behavior and opinions inconsistent with groups or with groups most people have differences, it will feel a pressure, which prompted him to tend in line with the group. So herd of consumer behavior took place. People tend to pick the most

likely.

In order to avoid spending could lead to economic risks, social risks, especially when people are faced with the inherent quality of the product is difficult to make careful judgments or commodity prices are high, often with friends, colleagues, and worship of the community as a reference groups, these groups act by an individual to be a useful reference information. Especially the worship of groups, consumer behavior is a direct result of demonstration imitate, imitate the example of imitators due to consumer behavior and feel happy. According to a study (2007 HK) Chinese consumers are more vulnerable than the U.S. consumer reference groups. 


\section{H2: The price has influence buying behaver}

\subsection{Relationship between raising economy and buying behaver}

One is to show luxury consumption through their own economic strength and social status: the other is through conspicuous consumption to maintain and create a personal relationship between survival and development of the network, the traditional Chinese cultural influence another luxury consumptions A performance of the "face" of consumption, in order to obtain personal "face." Even many people borrow money to buy a luxury. Vassal social need for most of the luxury consumption, the human resource is an intangible asset, it is often their interpersonal lives a very important part in the communication process are usually able to represent the product owners taste, knowledge, achievement and value standards. This is why a large number of middle-class people to buy luxury goods motives. And there will be reciprocity in China since ancient times, courtesy light weight friendship to reciprocate traditional culture. Dinners are interpersonal and engaging in commercial activities a commonly used method, but the severity is often one kind of gift component sincere reflection. Interpersonal communication is a very important emotional event, visitors will appear during outbound tourism shopping behavior, and in the buy local souvenirs will not give priority to buy domestic, wellknown, with local characteristics of the product as the preferred For example, we everyone knows the Japanese Shiseido "cosmetics, France's" Hennessy "wine, Swiss" Rolex "watches and so on, these famous luxury brand is also in the scope of their choice.

\section{H3: the raising economy has influence buying behaver}

\subsection{Relationship between quality and buying behaver}

Consumers have a tendency to kind of consumer goods in the choice of not only consider the performance of excellent product quality at the same time bring more attention to the extension of the value of products they buy is not just a commodity, but enjoy this luxury when purchasing The feelings of distinguished service, and this service allowed enough to feel that he is an elegant, the identity of the successful people, are also brought to experience this service to give its psychological implications of sexual stimulation, creating a sense of superiority. This article from the perspective of outbound tourism, outbound process for luxury consumption motives were analyzed, pointing out the motivation to buy luxury goods abroad mainly by price, conformity and imitation, show off, excellent quality composed of five major factors, but because of the level and ability of theoretical research on outbound tourism is still shallow, its lack of standardized management policy-depth study, which will be the direction of future research

\section{H4: quality has influence buying behaver}

\subsection{Relationship between attitude and buying behaver}

Nowadays,the number of Chinese rich people is rising. Chinese Luxury goods consumers actually were women and youth, Chinese women and the young age between generation of $80 \mathrm{~s}$ and $90 \mathrm{~s}$ are the major group of the Luxury goods consumer. A huge number of consumer are not rich but they still prefer the Luxury goods. According to the Roland Berger(Berger, 2012) 60\% of the Luxury goods consumers in China between age 20-39. In western country only $38 \%$ of consumers belong to that age group. Since 2010 to 2012 young age consumers raising from $25 \%$ to $46 \%$ (The Boston Consulting,2012). In western countries most of the Luxury consumers only spend $4 \%$ of they wealth to purchase Luxury, but in China the number of low-tier class people purchasing Luxury goods is raising. They could spend $40 \%$ of Luxury goods to buy Luxury goods even more. Since the economic growing in China. People start to know about Luxury brands. People purchase Luxury goods for a lots of reason. Most of them for self-awareness and political bribery. With increasing exposure to luxury brands, Chinese consumers have started to develop agood knowledge of brands. The previously mentioned KPMG survey indicated that their respondents recognized 59 luxury brands in 2012, up from 57 in 2010 and 43 in 2008, and more than half of the respondents preferred to purchase well-known luxury brands, and almost $70 \%$ of the respondents would pay a premium for well-known brands. Moreover, many luxury consumers in China are beginning to appreciate the brand's heritage and their purchasing decisions are often based on the rich cultural heritage associated with the brand. Chinese consumers greatly appreciate the royal association and are more inclined to view the brand as being high class and high quality. Riding the boom of the e-commerce sector in China, many luxury retailers in China are making huge digital marketing efforts to increase brand equity. Social media has become an increasingly common marketing tool. Chinese consumers are becoming more technology savvy and are increasingly getting used to using social media to interact with brands, provide comments on products, and find new brands. According to a report by PricewaterhouseCoopers19, consumers in China are more actively engaged with social media: 57\% of Chinese shoppers followed the brands on social media.(Berger,2012)

\section{H5: The attitude has influence buying behaver}




\section{1 research method}

\section{Research Methochology}

In the process of making this research, there are two method or ways which different and distinguish to each others; there are quantitative and qualitative method. The main difference thing between quantitative and qualitative is quantitative method is more focused on the number and utilizing of statistical tools, on the other side qualitative method is more concern on the comparison and usage of many theories from various of sources. However both of the methods have it own advantages and disadvantages.

According to Render, Stair, JR, and Mich. Hanna(2009) quantitative analysis is:

"Quantitative Analysis is the scientific approach to managerial decision making. Whim, emotions, and guesswork are not part of the quantitative analysis approach"

A quantitative method or approach is often being used with aim to verify and prove existing theories or test hypothesis developed based from the previous research or study. In the other side qualitative method is require its user to have a deeper understanding of the study problem, collecting, analyzing and interpreting that cannot be expressed in numbers. According to Denzin and Lincoln(2005) qualitative research or method is

"Qualitative research involves an interpretive and naturalistic approach, which means that qualitative research study things in their natural settings, attempting to make sense of or to interpret phenomena in terms of the meanings people bring to them"

Qualitative method is often used with aim to gain understanding of underlying reasons and motivations, to provide insights into the setting of a problem, generating idea or hypotheses for later or future research, and the last is to uncover prevalent trends in thought and opinion. However in this researcher, the researcher decided to chose quantitative method or research to conduct this study.

\subsection{Sampling}

The target population of this study consisted of Luxury Goods buyers in China Mainland. The Method of spreading questionnaire through China Luxury goods tribune and Google Drive. The data was collected from $15^{\text {th }}$ of October until $15^{\text {th }}$ of November , 2013.

\subsection{Data collection}

During this research date were collected through online information collection and questionnaire method. The question consist of Chinese customer buying behaver, shopping attitude and demographic. Which is adopt from previous research done by Cooper and Schindler(2006). Data were collected over a two month period during October until November. from age of $18 \mathrm{~s}$ to 60 s by Chinese people who have owe-ned Luxury goods. Data were collected by 11 question in two sections. Section A is about personal shopping behaver. It focused buy customer buy Luxury goods attitude and psychological, it will deeply researched by Why people choose to buy Luxury goods. Section B will be focused by what kind of factors that influence Chinese to buy a lots of Luxury goods.

The questionnaire respondents had to choose one out of five responses provided for each statement. The available responses were ranged from 1 until 5 which represent respondents' agreements toward the statements

Statistical Package for Social Science (SPSS) V. 16.0 Refers to the free library by Farlex about Statistical Package for Social Science (SPSS) is the most widely program or software that used to analyze data; for example basic statistical procedures such as frequencies, t-test, linear regression, multiple regression, means, factor analysis, and so on. In this research, the researcher will use SPSS to analysis the data that get from the questionnaire.

\subsection{Validity Test:}

The validity test show how far questionnaire able to measure what the researcher want measure in this study. The validity test help the researcher to ensure that each of question that asked in the questionnaire is the right and appropriate question which each of question able to measure what the researcher want to measure. The Pearson's correlation coefficient is using to measure the validity of variables in research. The coefficient of correlation of Pearson Product Moment can be based on the actual values of $\mathrm{X}$ and $\mathrm{Y}$. The equation as follow: The Formula is:

\section{Source: Berenson, Levine\& Timothy C. Krehbiel (2011)}

Where:

$\mathrm{n} \quad=$ the number of paired observations

$\Sigma X=$ the $X$ variable summed

$\Sigma \mathrm{Y}=$ the $\mathrm{Y}$ variable summed

$\Sigma \mathrm{X} 2=$ the $\mathrm{X}$ variable squared and the squares summed

$(\Sigma X) 2=$ the $X$ variable summed and the sum squared 
$\Sigma \mathrm{Y} 2=$ the $\mathrm{Y}$ variable squared and the squared summed

$(\Sigma Y) 2=$ the $Y$ variable summed and the sum squared

$\Sigma \mathrm{XY}=$ the sum of the product of $\mathrm{X}$ and $\mathrm{Y}$

According to Sugiyono (2006) in Rahmawati research (2005) state that "item which has high positive correlation with total score means that item has high validity"minimum standard in order to fulfill validity test is if $r=0.3$, where if $r<0.3$ is categorize as invalid. In this research, the researcher use 0.05 for significance level in the validity test.

\subsection{Reliability test:}

Reliability is the consistency of a set of measurements or of a measuring instrument, often used to describe a test. Reliability is the ability of a measurement instrument to measure the same thing each time is used (Kultar Singh, 2010). In the research, Cronbach's alpha is used as the formula to test the reliability of the data. Cronbach's $\alpha$ is a coefficient use to rate the correlation of items in a test, teh coefficient of the reliability is range between 0 until 1 . The value is close 1 , which means that the reliability is better. If the value close 0 , the reliability of the data used become less, variable is considered relibale if it has the value more than 0.70 . the Cronbach $\alpha$ formular is:

$$
\alpha=\frac{N \bullet \bar{r}}{1+(N-1) \bullet \overline{\mathrm{r}}}
$$

Where:

$\mathrm{N}=$ the number of components (items or test lets)

$\alpha=$ instrument reliability's coefficient

$\bar{r}=$ the average inter-item correlation among the items

In this research, the calculation process is help by SPSS 20 software as a tool.

Table 3.5 Reliable Value
\begin{tabular}{|l|l|l|}
\hline No. & Interval & Criteria \\
\hline 1 & $<0.200$ & Very low \\
\hline 2 & $0.200-0.399 \ldots$ & Low \\
\hline 3 & $0.400-0.599 \ldots$ & Pass \\
\hline 4 & $0.600-0.799 \ldots$ & High \\
\hline 5 & $0.800-1$ & Very high \\
\hline
\end{tabular}

Decision Process:

Source: conducted by the researcher

a. if the instrument has reliability coefficient point $\geq 0.6$, so it can said as reliable

b. if the instrument has reliability coefficient point $\leq 0.6$, so it can said as not reliable.

\subsection{Measurement Scale}

The Likert Scale was developed by RensisLikert. It is the most frequently used variation of the summed rating scale. Summed rating scales consist of statements that express either a favorable or an unfavorable attitude toward the object of interests. The participant is asked to agree or disagree with each statement. Each response is given a numerical score to measure the participants overall attitude Cooper and Schindler (2006).

In this research, data is interpreted using five-Likert ScaleMalhotra, (2010) as the same as the basis for the interpretation of the result of the compute data where the boundary of numeral and option includes:

\section{SPSS}

\begin{tabular}{|l|c|}
\hline \multicolumn{1}{|c|}{ Relative Grading Statement } & Score \\
\hline Strongly Agree & 5 \\
\hline Agree & 4 \\
\hline Neither Agree / Disagree (Neutral) & 3 \\
\hline Disagree & 2 \\
\hline Strongly Disagree & 1 \\
\hline
\end{tabular}

This computer software would be used to input the respondents' answers, testing the instrument validity and reliability, and present respondents' answers.

Microsoft Excel

This computer software would be used to collect the answers of questionnaire.

\section{Weighted mean}

The weighted mean is known as statistical technique which enables us to calculate an average that takes into account the important of each value to the overall total ( Levin \& Rubin,1998) 
The formula of weighted mean is:

$$
\overline{x_{w}}=\frac{\sum(\mathbf{w} \cdot \mathbf{x})}{\sum[g}
$$

$\overline{x_{w}}=$ symbol for the weighted mean

$\mathrm{W}=$ weight assigned to each observation

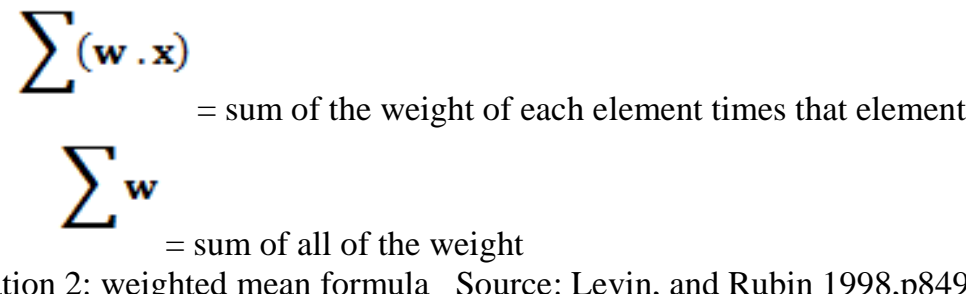

Equation 2: weighted mean formula Source: Levin, and Rubin 1998,p849

\section{Results Respondents Profile}

This chapter will showed all the important findings that have the researcher have got from study. Based on the survey result, approximately, $73 \%$ of the samples are female. The $27 \%$ of the samples are male. The age majority of respondents are $18-25(21 \%)$, age $25-35(32 \%)$, age $35-45(35 \%)$, age $45-55(12 \%)$. The $26 \%$ of the samples they are students. The $74 \%$ of the samples are employees, business man or house wife.

Validity:

The researcher base on the independent variables, dependent variable, and the Likert Scale measurement, build the questionnaire below as the table 3.3.

Each variable in questionnaire has five questions as listed below. The independent variable is marked as $\mathrm{X}$, and dependent variable is marked as $\mathrm{Y}$.

Independent variable can be described as the variable that is manipulated by the researcher, "thereby causing an effect on the dependent variable" (Cooper and Schindler, 2006). It is the variable that can be manipulated, changed, or altered by the experimenter, independently of any other variable. Dependent Variable is the variable whose value is dependent on the experimenter's manipulations.

\subsection{Table 1:}

\begin{tabular}{|c|c|}
\hline No. & Question \\
\hline \multicolumn{2}{|c|}{ X1: Values } \\
\hline $\mathrm{X} 1$. & Owning Luxury goods demonstrates success and social status \\
\hline $\mathrm{X} 2$. & Appreciate superior quality of Luxury goods,not just of the brand \\
\hline $\mathrm{X} 3$. & Own Luxury goods for sele-reward \\
\hline X4. & Own Luxury can bring confidence \\
\hline $\mathrm{X} 5$. & I own Luxury goods because they are popular in my social circle \\
\hline \multicolumn{2}{|c|}{ X2: Attitude } \\
\hline X6. & They are successful \\
\hline X7. & 7. They have good taste \\
\hline X8. & 8. They are fashionable \\
\hline X9. & 9. They are showing off, flashy \\
\hline $\mathrm{X} 10$. & 10. They are wasting they money \\
\hline \multicolumn{2}{|c|}{ X3: Activities } \\
\hline $\mathrm{X} 11$. & 11. You like contacting friends any time \\
\hline $\mathrm{X} 12$. & 12. You can not live without smart phone \\
\hline X13. & 13. You always listening music with your smart phone \\
\hline $\mathrm{X} 14$. & 14. You always pay attention to the update of new technology or new features in smart phone \\
\hline $\mathrm{X} 15$. & 15. You always are influenced by your friends or your emotion to buy products \\
\hline \multicolumn{2}{|c|}{ Y4: Purchasing Motivation } \\
\hline Y1. & 16. Loving the designer \\
\hline Y2. & 17. Loving the brand \\
\hline Y3. & 18. Purchasing the quality \\
\hline Y4. & 19. Purchasing the design \\
\hline Y5. & 20.purchasing the style \\
\hline
\end{tabular}

Source: conducted by the researcher

Independent variable $(\mathrm{X})$ in this research is lifestyle which indicated by three variables, attitude, values, and activities. Dependent variable (Y) in this research is consumer purchasing motivation of Luxury Goods . It is 
taken as the independent variable since this research studies the effect of this program towards as Chinese customer.

\subsection{Table2:}

KMO and Bartlett's Test

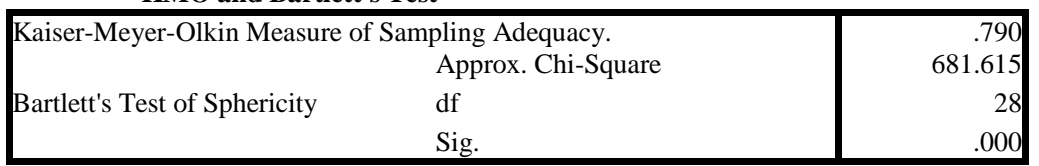

Which variables are appropriate to be included in the next analysis. The measurement is based on the communalities table. The result on the extraction of the communalities table should above 0.500(Mueller et al, 1978). The Communalities Table below shows the eight valid variables that pass the standard.

\subsection{Table 3:}

Source: IBM SPSS Statistic 20

\begin{tabular}{|l|r|r|r|}
\hline & \multicolumn{1}{|c|}{ Initial } & Extraction & Validity \\
\hline X1 & 1.000 & .779 & Valid \\
X2 & 1.000 & .690 & Valid \\
X5 & 1.000 & .527 & Valid \\
X7 & 1.000 & .594 & Valid \\
X8 & 1.000 & .715 & Valid \\
X9 & 1.000 & .706 & Valid \\
Y4 & 1.000 & .836 & Valid \\
Y5 & 1.000 & 540 & Valid \\
\hline
\end{tabular}

After finish reducing the variables, the next step is factor extraction . It is important to do the factor extraction to figure out the latent factors by combining the valid variables that have significant similarities. There are several ways to extract the factor. Extraction communalities are estimates of variance in each variable accounted for by the factor in the factor solution. Because small values indicate variables that do not fit well with the factor solution, so this table is already dropped the small values from the analysis. The extraction communalities for this solution are acceptable

\subsection{Table 4}

Total Variance Explained

\begin{tabular}{|c|c|c|c|c|c|c|c|c|c|}
\hline \multirow[t]{2}{*}{$\begin{array}{l}\text { Compone } \\
\text { nt }\end{array}$} & \multicolumn{3}{|c|}{ Initial Eigenvalues } & \multicolumn{3}{|c|}{$\begin{array}{c}\text { Extraction Sums of Squared } \\
\text { Loadings }\end{array}$} & \multicolumn{3}{|c|}{$\begin{array}{c}\text { Rotation Sums of Squared } \\
\text { Loadings }\end{array}$} \\
\hline & Total & $\begin{array}{c}\% \text { of } \\
\text { Variance }\end{array}$ & Cumulative \% & Total & $\begin{array}{c}\% \text { of } \\
\text { Variance }\end{array}$ & $\begin{array}{c}\text { Cumulativ } \\
\text { e } \%\end{array}$ & Total & $\begin{array}{c}\% \text { of } \\
\text { Variance }\end{array}$ & $\begin{array}{c}\text { Cumulative } \\
\%\end{array}$ \\
\hline 1 & 3.667 & 44.722 & 44.722 & 3.261 & 44.722 & 44.722 & 2.142 & 33.872 & 33.872 \\
\hline 2 & 1.590 & 17.356 & 63.078 & 1.590 & 17.356 & 56.078 & 2.585 & 31.322 & 63.194 \\
\hline 3 & 728 & 8.393 & 73.470 & & 7.192 & 63.470 & 1.030 & 7.355 & 62.549 \\
\hline 4 & 583 & 7.109 & 80.679 & & 7.103 & 70.679 & 1.023 & 7.307 & 69.856 \\
\hline 5 & .548 & 6.476 & 87.155 & & 6.387 & 77.155 & 1.022 & 7.299 & 77.155 \\
\hline 6 & .456 & 5.325 & 93.580 & & & & & & \\
\hline 7 & 276 & 3.778 & 97.358 & & & & & & \\
\hline 8 & .251 & 3.189 & 98.547 & & & & & & \\
\hline
\end{tabular}

In table 3 , to get the easier and simpler way in making variable interpretation, researchers decided to consider rotated component matrix as the standard. the leftmost section shows the variance explained by the initial solution. Only four factors in the initial solution have eigenvalues over than 1, This suggests that four latent influences are associated with service usage, but there remains room for a lot of unexplained variation. The second section of this table shows the variance explained by the extracted factor before rotation.

\subsection{Table 5 :}

Rotated Component Matrix ${ }^{\mathrm{a}}$

\begin{tabular}{|l|c|c|c|c|c|}
\hline & \multicolumn{5}{|c|}{ Component } \\
\cline { 2 - 6 } & 1 & 2 & 3 & 4 & 5 \\
\hline X3 & .872 & & & & \\
X4 & .854 & & & & \\
X2 & .659 & & & & \\
X10 & .903 & & & & \\
\hline
\end{tabular}




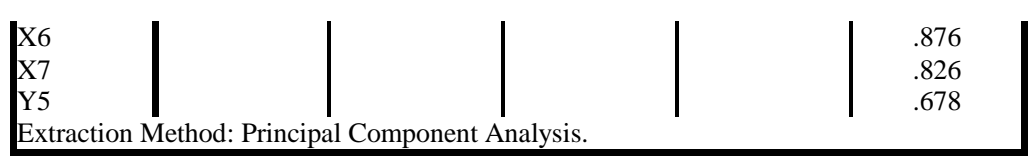

Table 4, Obtaining a factor solution through principal components analysis is an iterative process that usually requires repeating the SPSS factor analysis procedure a number of times to reach a satisfactory solution. It shows the Rotated Component Matrix. All the variables are over than 0.5, it means that all the questions are valid.

Reliability:

Reliability Statistics

\begin{tabular}{|r|r|r|}
\hline Cronbach's Alpha & $\begin{array}{c}\text { Cronbach's Alpha } \\
\text { Based on } \\
\text { Standardized Items }\end{array}$ & N of Items \\
\hline .806 & .796 & 14 \\
\hline
\end{tabular}

Minimal value for reliability test using Cronbach Alpha is 0.7 and this research result reliability test value is 0.756 , mean the questionnaire is relatively consistence.

\subsection{Discussion:}

From this data analysis, we know that in these four factors (value, attitude, activities and purchase motivation), the last three factors, that are attitude, activities and purchase motivation is important factors, and the value is less important than other three factors. It means that for Chinese Luxury goods purchaser the price, self-awareness and the beautiful design with good quality is the most important reason that Chinese people love Luxury goods very much.

\subsection{Conclusion}

\section{Conclusion and Recommendation}

This paper discussed luxury goods by trying to answer why luxury goods are so popular in China, as well as the economic impact of luxury goods. Starting with the first question on why China become the largest Luxury goods purchase country, it seems impossible to pinpoint this fact to a single reason. Instead, numerous factors, both economic and psychological, factor in customers' decisions to buy them. Many luxury goods exhibit superior quality compared to goods from other brands. In these cases, luxury goods can be seen as worthwhile investments for people buying them. Automobiles, jewelry, and other goods have clear advantages for paying more. For jewelry, the gem may be clearer or cut more intricately; for automobiles, performance may be better. In some cases, though, luxury goods offer no visible benefits for their price. Although identical products may go through different processes to be sold on the market, sometimes it is difficult to discern why people should pay such hefty premiums for the products. In cases such as these, status consumption comes in. While there may be several different motivations for status consumption, the general goal is identical: oftentimes consumers will pay premiums for luxury goods with no significant differences in quality simply to reflect a high status.

\subsection{Recommendation}

The Chinese Luxury Goods customer is different with western Luxury owners. The western Luxury owners around age of 30 to 70, but Chinese around age of 25 to 45. (Zhu, 2007)Some of them they are rich, but a big volume of customers overdraft to buy luxuries. They can spend $70 \%$ of they income for purchase Luxury goods. The Chinese customer have to improve they knowledge of the Luxuries. For purchase Luxury is not for showing off. Is a taste of the life and is must be under good financial. The Young people is the main power of Chinese customers, is not a right phenomenon. For Chinese people, the culture and history of luxuries is still far behind. Many people buying luxuries are to show off, and people treat others very much on appearance just by the first glance. By general understanding in China, wearing luxury cloths, driving luxury cars and living in luxury houses are the prove of wealth, but Chinese people don't know too much about how to match these luxuries to their life status. Most Chinese consumers just match luxuries to fortune, but they don't understand the reality behind. Chinese people have to understand the Luxury culture, learn how to match the different lifestyle.

\section{Acknowledgment}

This research paper is made possible through the help and support from everyone, including: parents, teachers, family, friends, and in essence, all sentient beings. Especially, please allow me to dedicate my acknowledgment of gratitude toward the following significant advisers and contributors: First and foremost, I 
would like to thank Mr. Suresh Kumah for his most support and encouragement. He kindly read my paper and offered invaluable detailed. Second, I would like to thank everyone from BA 2011 Retail class, they have help a lot with this research paper.

Finally, I sincerely thank to my parents, family, and friends, who provide the advice and financial support. The product of this research paper would not be possible without all of them.

\section{Bibliography:}

[1]. Alexander, P., Ryan, R., \& Deci, E. (January 01, 2000). Intrinsic and Extrinsic Motivations: Classic Definitions and New Directions. Contemporary Educational Psychology, 25, 1.

[2]. Bain \&CO. BAIN \&COMPANY PROJECTS 10\% SURGE IN WORLDWIDE LUXURY GOODS SALES IN 2010, ERASING RECESSIONARY DECLINES. Www.bain.com. Bain \&CO., Altagamma, 18 Oct. 2010. Web. 15 Nov. 2011.

[3]. Chadha, R., \& Husband, P. (2010). The cult of the luxury brand: Inside Asia's love affair with luxury. London: Nicholas Brealey International.

[4]. Charles Edouard Bouee.(2012) A brand awareness upgrade "Welcoming a new era in the Chinese luxury market"

[5]. "China revises 2007 GDP growth rate to 13\%". Xinhuanet. 2009-01-15. Retrieved 2009-01-15.

[6]. Copper, Donald R \& Schindler Pamela, S. (2006), Business Research Methods, The McGraw-Hill Companies

[7]. Nstructional Conversations in Native American Classrooms (1994). Center for Applied Linguistics: Online Digests (5).

[8]. Park, Jung-Dong (2004). The Special Economic Zones of China and Their Impact on Its Economic Development. Greenwood Press.

[9]. Roland Berger - Chinese consumers report - Luxury; A brand awareness upgrade. Welcoming a new era in the Chinese luxury market, October 2012

[10]. The Boston Consulting - The Age of the Affluent Group, November 2012

[11]. Vallerand, R. J. (March 08, 1993). The Academic Motivation Scale: A Measure of Intrinsic, Extrinsic, and Amotivation in Education. Educational and Psychological Measurement, 52, 4, 1003-17.

[12]. World Luxuary Association - Chinese overseas luxuary goods consumption during the Spring Festival,January 2013

[13]. Wood, Zoe. "LVMH's 'remarkable' Half-year Results Reveal Luxury Is Back in Fashion." The Guardian. Guardian News and Media, 26 July 2011. Web. 20 Feb. 2012.

[14]. Wong, N. Y., \& Ahuvia, A. C. (1998). Personal taste and family face: Luxury consumption in Confucian and Western societies. Psychology \& Marketing, 15(5), 423-441.

[15]. 5 KPMG - Global Reach of China Luxuary, January 2013

\section{The Attitude, motivation influence people's buying Luxury goods: A survey of Chinese in China}

\section{Part 1}

In this section you are asked to write down information about yourself and your work.

Title

Section

Age: $18-25(\quad)$

/

Sex (circle as appropriate): 1. Male 2. Female

Income/monthly(account as US dollar)

Last completed education

Have you ever buy Luxury goods: yes( ) no( )

\section{Part 2}

In this section you are asked to give an opinion on how much the following statement in accordance with the state of the company.

1 for "strongly disagree", 2 for "disagree", 3 for "neutral", 4 for "agree" and 5 for "strongly agree"

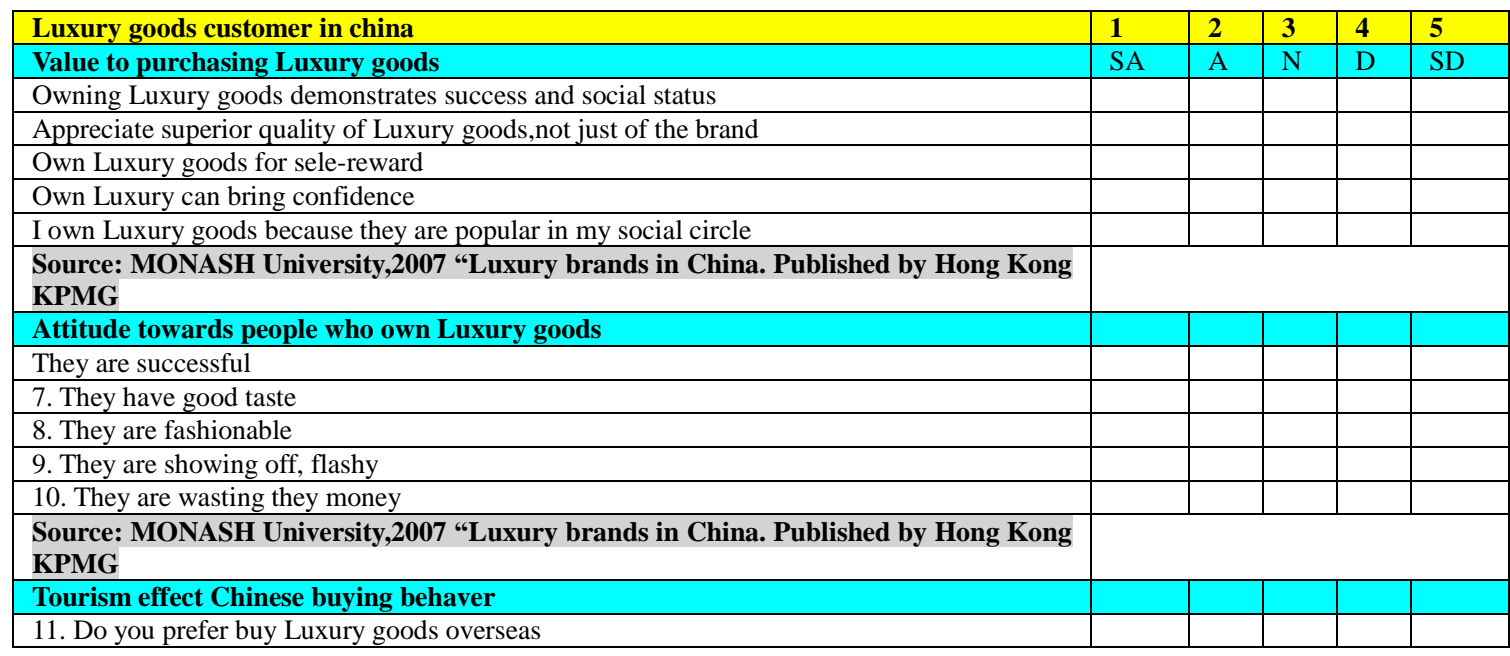


The Attitude, motivation influence people's buying Luxury goods: A survey of Chinese in China

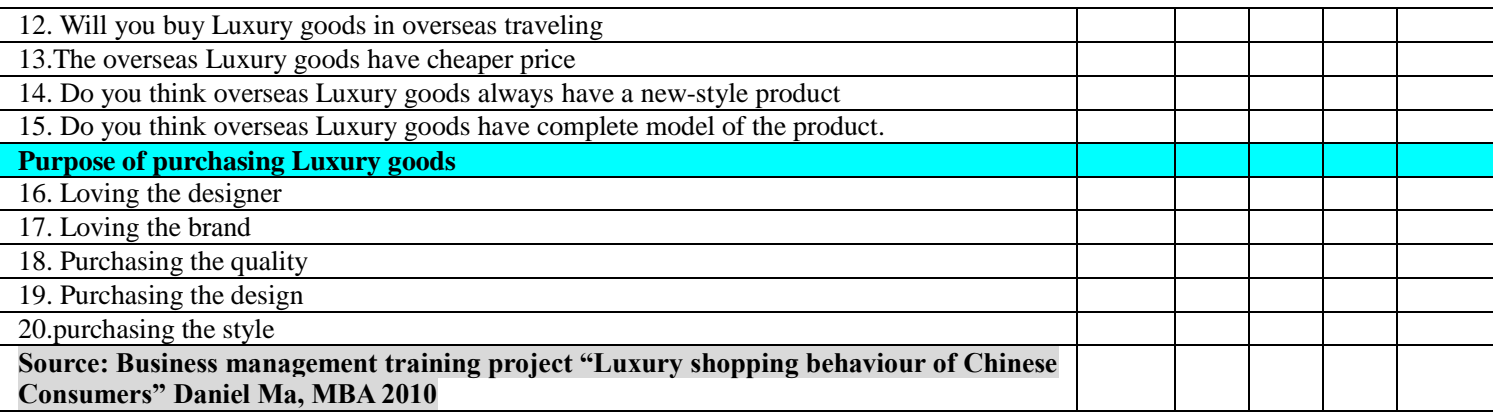

